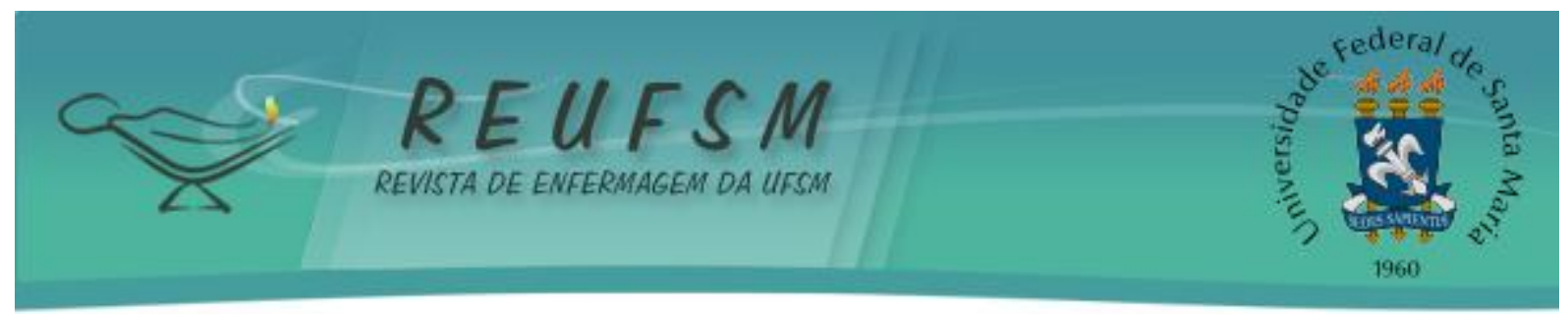

ARTIGO ORIGINAL

\title{
A VIVÊNCIA DA AMAMENTAÇÃO NA ÓTICA DE MULHERES: CONTRIBUIÇÕES PARA A ENFERMAGEM
}

\section{THE EXPERIENCE OF BREASTFEEDING IN WOMEN'S PERSPECTIVE: CONTRIBUTIONS TO NURSING}

\section{LA EXPERIENCIA DE LA LACTANCIA EN LA PERSPECTIVA DE MUJERES: CONTRIBUICIONES A LA ENFERMERÍA}

Doi: $10.5902 / 2179769215409$

\author{
Laís Antunes Wilhelm ${ }^{1}$ \\ Carolina Carbonell Demori ${ }^{2}$ \\ Camila Neumaier Alves ${ }^{3}$ \\ Camila Nunes Barreto ${ }^{4}$ \\ Luiza Cremonese ${ }^{5}$ \\ Lúcia Beatriz Ressel ${ }^{6}$
}

RESUMO: Objetivo: conhecer a vivência de mulheres em relação ao aleitamento materno. Método: estudo qualitativo de caráter descritivo. Participaram onze mulheres usuárias de uma unidade básica de saúde, que foram captadas por meio de convite aleatório. Os dados foram coletados por meio de entrevista semiestruturada, sendo a análise temática o procedimento analítico adotado. A pesquisa seguiu as normas da resolução 196/96 e foi aprovada pelo Comitê de Ética em Pesquisa CAAE $n^{\circ}$ 0165.0.243.000-11. Resultados: apontaram as categorias: Saberes populares e científicos acerca do aleitamento materno de mulheres que o vivenciaram e influências familiares na construção do conhecimento no processo do aleitamento materno. Conclusão: as mulheres entrevistadas acreditam no efeito protetor do aleitamento materno e que o mesmo deve ser ofertado de forma exclusiva até os seis meses de idade da criança, além disso, sentem-se influenciadas por aspectos culturais, referindo à relevância da opinião de familiares e profissionais da saúde. Descritores: Enfermagem; Aleitamento materno; Saúde da mulher.

ABSTRACT: Aim: to know the experience of women about breastfeeding. Method: qualitative descriptive research. The participants were eleven women, randomly invited from the users of a basic health center. The data collection was made through semistructured interviews and the analytical procedure was thematic analysis. The research followed the 196/96 resolution and was approved by the Research Ethics Committee under number 0165.0.243.000-11. Results: the categories that emerged Popular and scientific knowledge regarding breastfeeding of women who have experienced and Family influences in the construction of knowledge in breastfeeding process. Conclusion: the interviewed women believe in the protective effect of breastfeeding and that it should be exclusively

\footnotetext{
1 Enfermeira. Mestre em Enfermagem. Universidade Federal de Santa Maria/UFSM. Santa Maria, RS, Brasil. Email: laiswilhelm@gmai.com

${ }^{2}$ Enfermeira. Mestre em Enfermagem. Universidade Federal de Pelotas/UFPEL. Pelotas, RS, Brasil. E-mail: carolinaufsm@hotmail.com

${ }^{3}$ Enfermeira. Mestre em Enfermagem. Universidade Federal de Pelotas/UFPEL. Pelotas, RS, Brasil. E-mail: camilaenfer@gmail.com.br

${ }^{4}$ Enfermeira. Mestre em Enfermagem. Universidade Federal de Santa Maria/UFSM. Santa Maria, RS, Brasil. Email: camilabarreto_6@msn.com

5 Enfermeira. Universidade Federal de Santa Maria/UFSM. Santa Maria, RS, Brasil. E-mail: lu_cremonese@hotmail.com

${ }^{6}$ Enfermeira. Doutora em Enfermagem. Universidade Federal de Santa Maria/UFSM. Santa Maria, RS, Brasil. Email: lbressel208@yahoo.com.br
} 


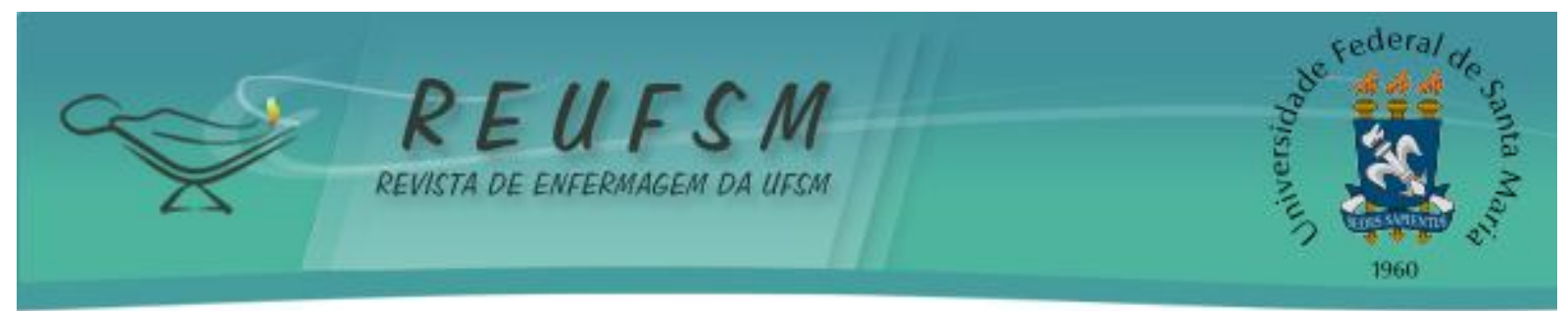

offered until the child is six month old. Moreover, they feel influenced by cultural aspects, reporting the relevance of the opinion of family and health professionals.

Descriptors: Nurse; Breastfeeding; Women's health.

RESUMEN: Objetivo: conocer la experiencia de mujeres con relación a la lactancia materna. Método: estudio descriptivo cualitativo. Participaron once mujeres que asisten a una unidad básica de atención de salud, elegidas a través de invitaciones al azar. Los datos fueron recolectados a través de entrevista semiestructurada, siendo el análisis temático el procedimiento analítico adoptado. La investigación siguió la Resolución 196/96 y fue aprobado por el Comité de Ética en Investigación CAAE 0165.0.243.000-11. Resultados: señalaron las categorías: el conocimiento popular y científico sobre la lactancia materna de mujer que han experimentado; influencias de la familia en la construcción del conocimiento en el proceso de la lactancia materna Conclusión: las mujeres creen en el efecto protector de la lactancia materna y que esta debe ser brindada de forma exclusiva hasta los seis meses de edad del niño, además, siéntense influidas por aspectos culturales, refiriéndose a la importancia de la opinión familiar y de profesionales de la salud.

Descriptores: Enfermería; Lactancia materna; Salud de la mujer.

\section{INTRODUÇÃO}

Amamentação ou Aleitamento Materno (AM), significa aleitar e nutrir o filho com o leite que produz, sendo popularmente visto como um comportamento natural. No entanto, é baseado no aprendizado, na experiência, na observação e em exemplos vivenciados pela mulher, estando vinculado a determinantes sociais e culturais, sejam eles de apoio ou de rejeição. ${ }^{1}$

Neste sentido, é preciso lembrar que a cultura expressa as nossas ideias, valores, atos e até mesmo as nossas emoções. As pessoas são conduzidas por uma construção de produtos culturais e ao mesmo tempo são extremamente variáveis, sujeitas a inúmeras influências, que se expressam por meio de símbolos e se organizam a partir de concepções e conceitos, na busca de significados. ${ }^{2}$

Nesta lógica, a valorização dos significados construídos na vivência das mulheres, relacionados ao $\mathrm{AM}$, pode desvelar as suas reais necessidades e ser um importante caminho para o entendimento deste evento. ${ }^{3}$ Este olhar para os saberes e práticas das mulheres permite a descentralização do foco clínico, que traz explicações fisiológicas e patologizantes, e favorece a fala, os significados nos sentimentos e emoções das mulheres em torno das experiências vividas.

Diante disto, este estudo tem como objetivo conhecer a vivência de mulheres em relação ao $\mathrm{AM}$ e como questão de pesquisa: como as mulheres vivenciam a amamentação? Justifica-se a importância de estudos nessa área para qualificação da assistência prestada a partir dos contextos nos quais as mães estão inseridas, valorizando sua percepção e significação acerca da amamentação.

Ademais, destaca-se que a temática em questão é referenciada na Agenda Nacional de Prioridades em Pesquisa em Saúde, que estimula a realização de estudos que visam ampliações do processo de amamentação na qualidade de vida da mulher. ${ }^{4}$ Esta Agenda apresenta como pressuposto respeitar as necessidades nacionais e regionais de saúde e aumentar a indução seletiva para a produção de conhecimentos e bens materiais e processuais nas áreas prioritárias para o desenvolvimento das políticas sociais. 


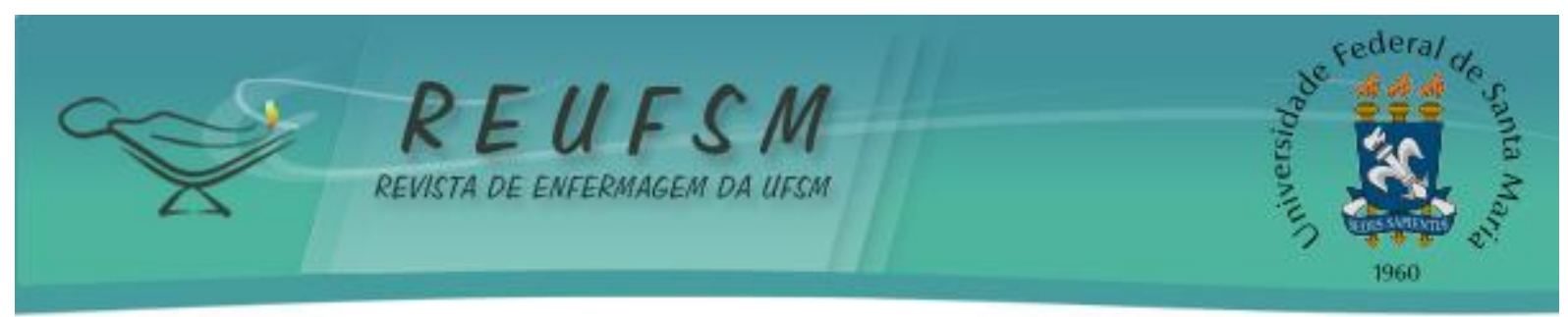

MÉTODO

Trata-se de uma pesquisa de campo do tipo descritiva com abordagem qualitativa. 0 método qualitativo aplica-se ao estudo das relações, representações, crenças e percepções, fruto das interpretações que as pessoas fazem a respeito de como vivem, como constroem suas vidas e a si mesmas. ${ }^{5}$

A pesquisa teve como cenário uma unidade básica de saúde do sul do país. As participantes da pesquisa foram 11 mulheres usuárias da unidade, as quais foram captadas por meio de convite aleatório. Nesta unidade há um programa de consultas de puericultura, que atende recém-nascidos e crianças até dois anos de idade, o qual foi selecionado para captar as nutrizes, pois as mães acompanhavam seus filhos nas consultas. Os critérios de inclusão foram: mulheres que amamentaram pelo menos até os seis meses e mulheres com mais de 18 anos.

A coleta de dados ocorreu entre os meses de abril a maio de 2011, por meio do uso da técnica de entrevista semiestruturada. A entrevista foi composta de questões fechadas para caracterização dos sujeitos e questões abertas referentes à temática em estudo, relativas aos conhecimentos e práticas das mulheres sobre à amamentação e também relacionadas a quem contribui para essa construção de saberes no processo do aleitamento materno, para posterior análise dos dados.

A análise dos dados foi fundamentada na análise temática, que é uma das modalidades da análise de conteúdo. A qual é definida como a descoberta dos núcleos de sentidos, que constituem uma comunicação acerca da frequência ou da presença de algum significado para o objeto que esta sendo analisado. ${ }^{5}$

Esta análise caracteriza-se pela realização de procedimentos sistemáticos e objetivos de descrição dos conteúdos das mensagens. A escolha da análise temática devese ao fato de esse ser um método rápido e eficaz na condição de se aplicar a discursos diretos e simples, embasado na regularidade das afirmações denotando, dessa forma, estruturas de relevância, valores de referência e comportamentos presentes ou subjacentes nos discursos. ${ }^{5}$

Para tal, realizou-se a leitura sistemática do material organizado previamente, e agruparam-se os fragmentos que se repetiam ou possuíam semelhança semântica nos diferentes depoimentos. Posteriormente, categorizaram-se os elementos constitutivos do tema, completando-se as três etapas de análise: pré-análise; exploração do material e tratamento e interpretação dos resultados obtidos. $\mathrm{Na}$ análise final, articulou-se os dados construídos durante a coleta ao referencial teórico, visando responder as questões da pesquisa. ${ }^{5}$

A pesquisa amparou-se pela condução ética, sendo assegurado e valorizado os aspectos éticos e legais no decorrer do estudo. Por conseguinte, os preceitos da Resolução n. 196/96 do Conselho Nacional de Saúde - Ministério da Saúde, que dispõe sobre diretrizes e normas que regulamentam a pesquisa envolvendo a participação de seres humanos, especialmente no que se refere ao Consentimento Livre e Esclarecido, foram cuidadosamente seguidos. $^{6}$

Iniciou-se o estudo após autorização da Secretaria do Municipal de Saúde do município e após aprovação do projeto pelo Comitê de Ética em Pesquisa da Universidade proponente sob o protocolo número 23081.008/2011-00 e Certificado de Apresentação para Apreciação Ética: 0165.0.243.000-11. O anonimato das participantes viabilizou-se com a utilização da letra A e seguido pelo sistema alfanumérico de apresentação dos dados. 


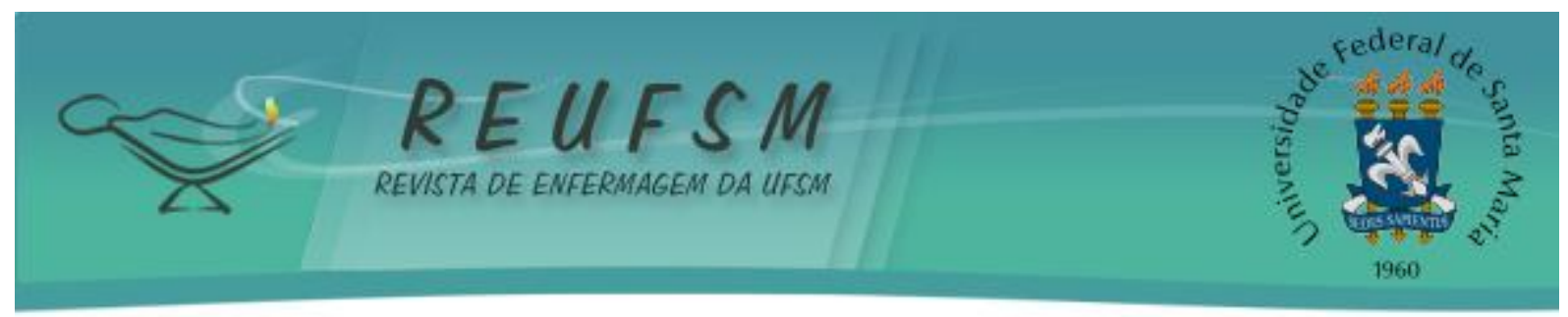

\section{RESULTADOS}

A idade das 11 mulheres entrevistadas variou de 20 a 55 anos, sendo sete na faixa etária entre 20 e 35 anos e quatro com idade superior a 35 anos. Em relação à escolaridade, duas entrevistadas possuíam o ensino médio completo; quatro referiram ensino médio incompleto; duas com ensino fundamental completo e outras duas com ensino fundamental incompleto. Quanto à ocupação, oito eram do lar; uma trabalhava em serviços gerais; uma era comerciante e uma aposentada. Sobre o estado civil, quatro declaram-se solteiras; três viviam em concubinato; duas afirmaram-se casadas; uma era divorciada e uma viúva. A paridade das entrevistadas variou entre um e cinco filhos.

Após a análise das falas das mulheres entrevistadas, emergiram as categorias referentes às questões envolvendo o $\mathrm{AM}$. São elas: Saberes populares e científicos acerca do aleitamento materno de mulheres que o vivenciaram e Influências familiares na construção do conhecimento no processo do aleitamento materno cujos principais resultados foram discutidos a partir do estabelecimento do diálogo com o referencial teórico, buscando alcançar nesse movimento a compreensão sobre o processo do AM.

\section{Saberes populares e científicos acerca do aleitamento materno de mulheres que o vivenciaram}

Em relação aos saberes e práticas das mulheres sobre a amamentação, foi destacado por elas, no momento das entrevistas, inicialmente, as vantagens sobre o $A M$ como protetor da saúde da criança, como nota-se a partir das seguintes falas:

O leite materno é bom para saúde do nenê, para criança se desenvolver mais e evitar muitas doenças. (A2)

O leite materno é importante para criança. Ajuda a evitar infecções, crescerem mais fortes. (A8)

O leite materno é a melhor coisa para saúde da criança, para não ter doenças. Várias doenças ele ajuda a não ter. Combate uma série de doenças, e meus filhos nunca tiveram doenças. A única que não amamentei, ao contrário, é cheia de alergias. (A10)

Ao serem instigadas a relatar sobre o que sabiam em relação à amamentação, as entrevistadas declararam que o leite materno é importante para evitar doenças, ajuda no desenvolvimento saudável e deve ser ofertado às crianças quando elas requisitarem. Assim o AM é considerado, como um vínculo protetor de enfermidades, o qual é essencial para a saúde de seus filhos.

Outro item observado nesta categoria, relatado por algumas das entrevistadas, é a necessidade de exclusividade do AM por um período de seis meses:

O benefício do aleitamento materno é que evita muitas doenças e é essencial até os seis meses. (A1)

Até os seis meses deve-se dar só o leite materno. Aí depois sim, incluir outros alimentos, mas continuar dando leite materno até os dois anos ou mais. (A8) 


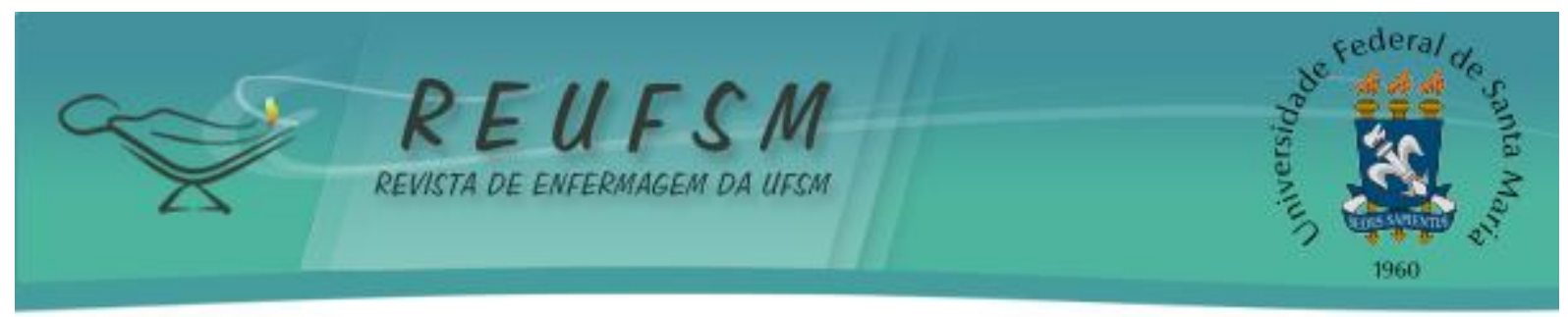

Nos primeiro seis meses de vida do bebê tem tudo que o bebê precisa no leite materno, não precisa dar chazinho, até mesmo água tem no leite. (A9)

A percepção destas mulheres é que até os seis meses de vida da criança deve-se dar o leite materno exclusivamente. Sabe-se que o Aleitamento Materno Exclusivo (AME) tem uma relevância na saúde das crianças e que o mesmo deve ser ofertado a elas por esse período, para atender suas necessidades.

\section{Influências familiares na construção do conhecimento no processo do aleitamento materno}

Nesta categoria foi possível perceber que as nutrizes, muitas vezes, são responsabilizadas pelo sucesso da amamentação. E que sua carga de conhecimentos prévios tem influência direta da sua família, que se constituí como elemento decisivo ao $A M$.

A família pode atuar, oferecendo apoio e incentivando a amamentação. Neste estudo, ela é citada como elemento integrante deste processo, sendo um personagem incentivador ao $\mathrm{AM}$, e tendo papel essencial na construção do conhecimento destas mulheres:

Minha família sempre me apoiou, sim para amamentar. (A1)

Quando meu seio empedrou, minha mãe minha avó me ensinaram colocar compressas quentes ou no banho quente e massagear. (A5)

Para tratar problemas nas mamas, minha avó ensinou a sempre lavar bem. (A9)

Minha mãe me ensinou passar manteiga de cacau para aquelas rachaduras. (A11)

Percebe-se a família, nesta pesquisa, como apoiadora e elemento importante na construção dos saberes relativos à amamentação, muitos destes passados de geração a geração de acordo com a cultura de cada família. Os significados trazidos pelos familiares, na prática do AM, confirmam a importância do mesmo para os membros daquela família, a qual transmite seus conhecimentos por meio das práticas de cuidado ao bebê incluindo a amamentação.

Esta unidade temática também evidenciou nos depoimentos que, em relação à construção do conhecimento nas práticas de cuidado sobre o $\mathrm{AM}$, alguns dos profissionais da área da saúde (enfermeiros e médicos) foram influentes, como podemos perceber pelas falas das entrevistadas:

Eu aprendi os cuidados com a enfermeira e com o médico do posto que faziam o meu pré-natal. (A4)

Colocava o próprio leite do peito nos mamilos, a enfermeira do hospital que ensinou para prevenir das fissuras. (A11)

Nas entrevistas, aparecem à construção de conhecimento sobre o processo do $A M$, cuidados que devem ser realizados, nos quais enfermeiros e médicos são responsáveis por tais informações. Pensa-se que na abordagem com nutrizes, o profissional de saúde precisa 


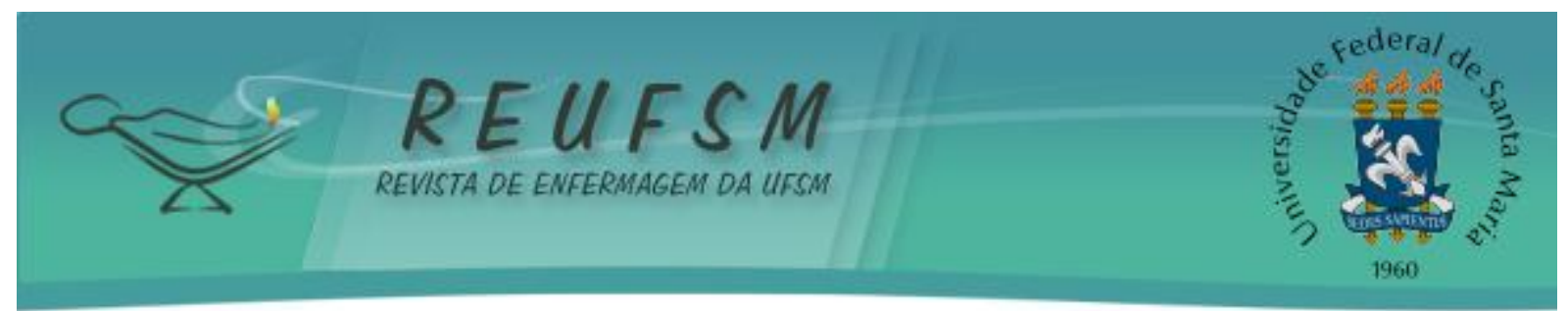

ser receptivo a crenças que envolvem a amamentação. Assim, surge a oportunidade de dialogar e ficar mais próximos das mulheres, orientando sobre suas reais necessidades.

\section{DISCUSSÃO}

Pode-se perceber o entendimento das mulheres sobre a relevância da amamentação, uma vez que para elas, amamentar pouco tempo pode resultar fraqueza na criança. Estudo indica a curta duração do AM como possibilidade de levar a doenças infecciosas. ${ }^{7}$

A presença de doenças nos bebês que não estão em AME pode estar associado ao fato de que as crianças ao consumirem outros alimentos apresentam maior risco de contaminação por patógenos. O leite materno é necessário tanto para a prevenção de doenças infecciosas, especialmente, das enfermidades diarreicas, como para o crescimento e desenvolvimento da criança, o qual é bastante dependente da satisfação das necessidades nutricionais. ${ }^{8}$

Compreende-se neste estudo, em consonância com outra pesquisa que as mulheres constroem o valor da prática da amamentação como benéfica para o bebê, tendo por base a experiência social. ${ }^{9}$ Assim como para as mulheres entrevistadas, o AME tem uma relevância na saúde das crianças, além de sustentar que o mesmo deve ser ofertado unicamente a elas até os seis meses de idade, para atender suas necessidades tendo sua manutenção até os dois anos de idade ou mais. ${ }^{10}$ As práticas alimentares devem ser entendidas a partir das condições sociodemográficas de cada família e das condições clínicas da gestação e do nascimento de cada criança, a fim de promover e sustentar o AM e a introdução de outros alimentos em momento oportuno. ${ }^{11}$

Quando se enfoca a prática da amamentação como um processo susceptível a influências múltiplas, os membros familiares são responsáveis por grande parcela de interferências sobre a decisão de amamentar. A casa e a família continuam sendo seu lócus e a experiência avaliza a opinião das pessoas mais próximas, num processo cumulativo de conhecimentos adquiridos ao longo dos anos, podendo ser vistas como sábias, valorizadas e respeitadas. ${ }^{9}$ A aproximação com a realidade de cada mulher e sua família, permite a identificação das práticas que vêm sendo repassadas dentro do contexto familiar, sendo possível a aplicação de suporte condizente com a realidade delas. ${ }^{12}$

A participação da família nos remete como algo importante no sentido de compartilhar a vivência e os sentimentos que envolvem o processo de amamentar. É possível perceber a dualidade da influência de familiares na amamentação, tanto de forma positiva, como contrária, em que na maioria das vezes, são os mais velhos, como mãe e avó, que influenciam na hora da amamentação, assim o cuidado do filho é um ensinamento que passa de geração para geração. ${ }^{13}$

A amamentação pode ser, portanto um ato natural, instintivo, biológico e próprio da espécie. Com esse pano de fundo as ações de enfermagem devem se orientar para apoiar e estimular as mulheres no que diz respeito ao $A M$, não thes imputando culpa pelo insucesso, seja pelos agravos à sua saúde ou simplesmente por não quererem amamentar. Acreditar que a amamentação é um recurso de magna importância para a saúde da criança, exige, dos profissionais de saúde, igual qualificação da crença de que esta prática só vale a pena ser exercida quando resulta em prazer, com o mínimo de desconforto e sacrifícios desnecessários, suportadas pelas mulheres.

Entende-se que, é preciso avançar e direcionar ações educativas que incluam a perspectiva de promoção da saúde às mulheres. Tal perspectiva deve possibilitar a compreensão das condições de vida, o envolvimento de suas famílias, e favorecer a autoconstrução delas como sujeito ativo. 


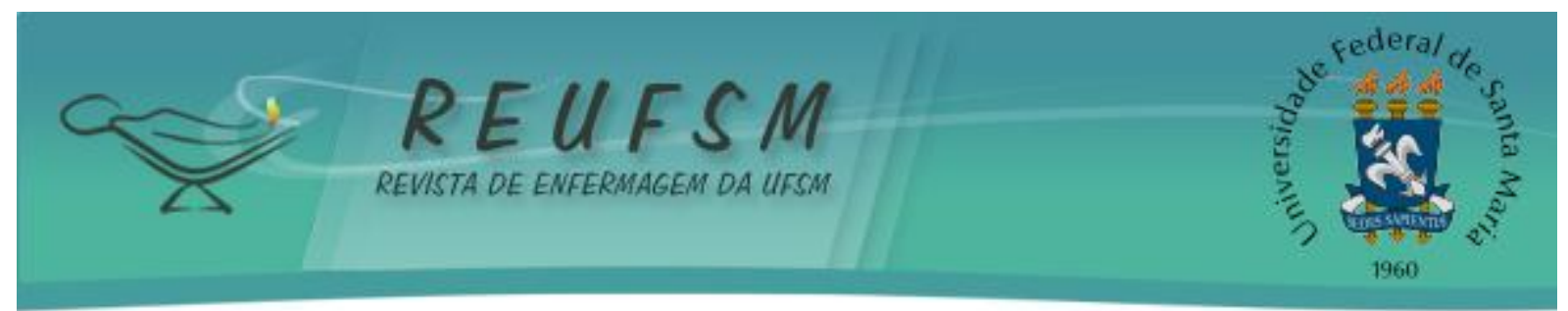

Diante disso, urgem medidas efetivas que ressignifiquem as ações educativas, preconizadas pelas políticas públicas de saúde em relação ao $A M .^{13}$ A sensibilidade e a disponibilidade do Enfermeiro, para estar com os pais e familiares que vivenciam o processo de AM, devem estar de acordo com ações, que reflitam em suas práticas, como profissionais de saúde, o reconhecimento da família como sujeitos de atos relevantes para a criança. ${ }^{14}$

Concorda-se que o AM é um ato socialmente aprendido e que deve ser orientado antes do nascimento do bebê, tanto para a mulher como para sua família. Logo, deve-se informar os benefícios da amamentação, as desvantagens do uso de leites não humanos, além das técnicas de amamentação, para aumentar a habilidade e confiança da mulher. ${ }^{15}$ Para isso, mostra-se necessária a compreensão da nutriz em todas as suas dimensões do ser mulher, considerando o meio em que se inserem os familiares e as pessoas do seu convívio.

Sendo assim, é preciso que o profissional atuante na assistência à nutriz tenha a visão voltada à peculiaridade de cada mulher e sua família, bem como ao contexto de suas relações, como vizinhança, amigos e outros elementos de influência social. ${ }^{12}$ Logo, pensa-se que é preciso compreender não apenas o evento biologicamente, mas também os aspectos sociais, culturais e psicológicos que circundam o universo desta família no apoio à amamentação.

Assim, as iniciativas para estimular o AM, representam um marco fundamental em relação à sua promoção, com efetiva participação dos serviços de saúde. ${ }^{16}$ Nesta direção, estratégias como a Iniciativa Hospital Amigo da Criança, proposta pela Organização Mundial da Saúde, têm sensibilizado e mobilizado os profissionais de saúde na área hospitalar, no sentido de uma verdadeira mudança de postura em prol do aleitamento materno.

Nos achados desta pesquisa, pode-se perceber que as mulheres obtinham informações referentes às vantagens e desvantagens do aleitamento materno mediante as consultas de prénatal da unidade de saúde à qual faziam o acompanhamento. É necessário destacar que durante o pré-natal, deve-se estabelecer uma conversa com as gestantes para que verbalizem o seu desejo ou não de amamentar e o que elas entendem como sendo bom para elas e para seus bebês, proporcionando assim um diálogo nesse âmbito.

0 atendimento de pré-natal é um momento propício para que as futuras mães possam tirar suas dúvidas e receber esclarecimentos a respeito do assunto. Cada mulher deve ser avaliada cuidadosamente, para que se possa perceber quais são as reais necessidades de orientações e quais as opções que devem ser oferecidas. ${ }^{8}$ Confirma-se assim, que as orientações relativas à amamentação no pré-natal, refletem no $A M$ e na saúde maternoinfantil, uma vez que os profissionais de saúde, principalmente o Enfermeiro, incluem orientações e discutem com a gestante e seus familiares sobre a prática do $A M$ e seus benefícios ao longo das consultas de pré-natal e grupos de gestantes. ${ }^{16}$

\section{CONSIDERAÇÕES FINAIS}

Os resultados desta pesquisa demonstraram que as mulheres sentem-se influenciadas por aspectos culturais, referindo à relevância da opinião de familiares e profissionais da saúde. Foi possível visualizar a importância de assistir a mulher que vivencia a amamentação, valorizando além da dimensão biológica, os fatores culturais que permeiam diretamente no ato de amamentar. A prática do AM é socioculturalmente condicionada na maioria das vezes à vivência de familiares e profissionais da saúde.

O emaranhado de elementos subjetivos apresentados pelas mulheres, nada mais é, do que a rede simbólica tecida por elas, que, como seres sociais expostos às influências do meio em que vivem, atribuem significados ao AM concernentes a interferência do cenário no qual estão inseridas.

A prática da amamentação é um processo susceptível a influências múltiplas, e os membros familiares são responsáveis por boa parcela de interferências sobre a decisão de 


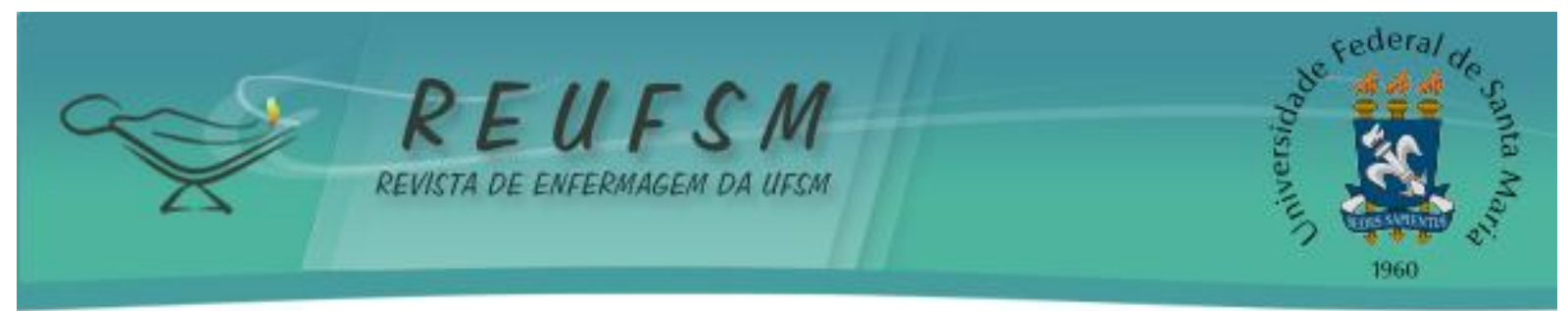

amamentar. A família foi identificada como importante fonte de apoio à amamentação, uma vez que por meio dela se constrói os saberes e práticas relativos à amamentação.

Sabendo da importância e da necessidade da amamentação, propõe-se ao final deste estudo, aos profissionais de saúde, que envolvam as mulheres e sua família nas ações de saúde para o preparo do AM, desde o pré-natal. Pensa-se que na abordagem com nutrizes, o profissional de saúde precisa ser receptivo e sensível à escuta destas mulheres, uma vez que o conhecimento destas tem fundamentação advinda deles.

Ressalta-se, que os profissionais de saúde não devem adotar uma posição autoritária, sendo necessário conhecer as mulheres, entendo-as e questionando-as a respeito de sua saúde, de seus valores e desejos. Ao proceder desta forma, surge a oportunidade de dialogar e ficar mais próximos da nutriz, apoiando-a e oferecendo ajuda. Destaca-se a importância de entender a dimensão do cuidado com o $A M$, voltado para o contexto que as mulheres vivem, valorizando e respeitando suas crenças, práticas de cuidado de saúde, hábitos, conhecendo a necessidade de cada uma.

Assistir a saúde da mulher no período da lactação exige habilidades específicas do profissional da saúde, pois os desafios diários desde a atenção pré-natal, por exemplo, não se restringem ao campo técnico-científico. Acolher a família, incorporar estratégias de aproximação das redes sociais, oportunizar espaços dialógicos, fortalecer saberes e práticas populares, e valorizar as representações culturais são algumas maneiras de compreender e oferecer novas possibilidades às mulheres em relação a sua saúde, visto que, deseja-se que elas sejam protagonistas de sua própria história e tenham prazer e satisfação com a prática do aleitamento materno.

\section{REFERÊNCIAS}

1. Junges CF, Ressel LB, Budó MLD, Padoin SMM, Hoffmann IC, Sehnem GD. Percepções de puérperas quanto aos fatores que influenciam o aleitamento materno. Rev Gaúcha Enferm [Internet]. 2010 [acesso em 2013 mar 31];31(2):343-50. Disponível em: http://dx.doi.org/10.1590/S1983-14472010000200020.

2. Geertz C. Interpretação das culturas. Rio de Janeiro: LTC; 1989.

3. Rocci E, Fernandes RAQ. Dificuldades no aleitamento materno e influência no desmame precoce. Rev Bras Enferm [Internet]. 2014 [acesso em 2014 dez 11];67(1):22-7. Disponível em: http:/ / www.scielo.br/scielo.php?pid=S0034-71672014000100022\&script=sci_arttext.

4. Brasil. Ministério da Saúde. Agenda nacional de prioridades de pesquisa em saúde. Brasília: Ministério da Saúde; 2008.

5. Minayo MCS. O desafio do conhecimento: pesquisa qualitativa em saúde. $10^{a}$ ed. São Paulo: Hucitec; 2010.

6. Brasil. Ministério da Saúde. Conselho Nacional de Saúde. Resolução CNS n 196, de 10 de outubro de 1996. Diretrizes e normas regulamentadoras de pesquisa envolvendo seres humanos. Brasília; 1996.

7. Lima DB, Fujimori E, Borges ALV, Silva MMS. Prática alimentar nos dois primeiros anos de vida. Rev Esc Enferm USP [Internet]. 2011 [acesso em 2013 mar 18];45(N Esp 2):1705-9. Disponível em: http://www.scielo.br/scielo.php?script=sci_arttext\&pid=S008062342011000800012.

8. Anversa ETR, Bastos GAN, Nunes LN, Pizzol TSD. Qualidade do processo da assistência pré-natal: unidades básicas de saúde e unidades de Estratégia Saúde da Família em 


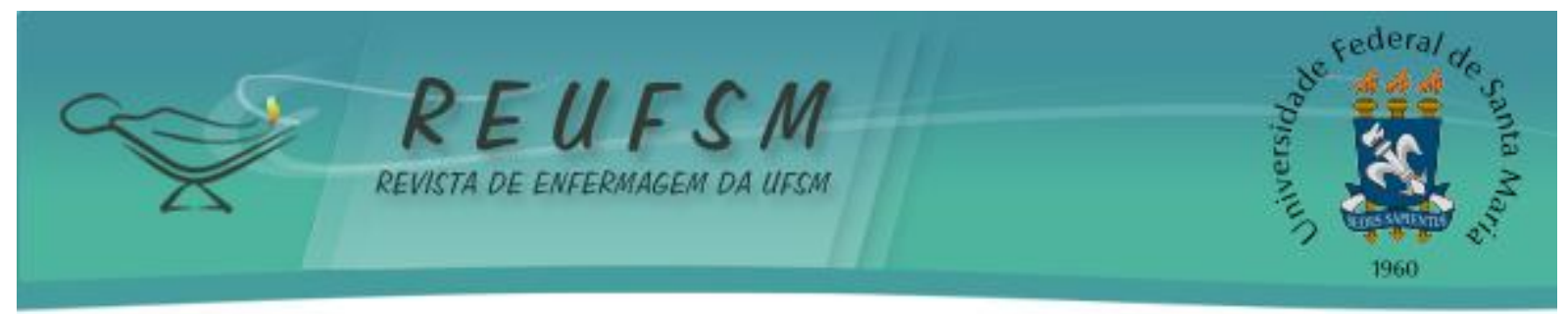

município no Sul do Brasil. Cad Saúde Pública (Rio de Janeiro) [Internet]. 2012 [acesso em 2015 jan 5];28(4):789-800. Disponível em: http://www.scielo.br/pdf/csp/v28n4/18.pdf.

9. Marques ES, Cotta RMM, Magalhães KA, Sant'Ana LFR, Gomes AP, Siqueira-Batista R. A influência da rede social da nutriz no aleitamento materno: o papel estratégico dos familiares e dos profissionais de saúde. Ciênc Saúde Coletiva [Internet]. 2010 [acesso em 2013 jan 10];15(Supl 1):1391-400. Disponível em: http: / /www.scielo.br/scielo.php?script=sci_arttext\&pid=\$1413-81232010000700049.

10. Soares AVN, Gaidzinski RR, Cirico MOV. Identificação das intervenções de enfermagem no sistema de alojamento conjunto. Rev Esc Enferm USP [Internet]. 2010 [acesso em 2014 dez 10];44(2):308-17. Disponível em: http: / /www.scielo.br/scielo.php?script=sci_arttext\&pid=S0080-62342010000200010.

11. Martins EL, Padoin SMM, Rodrigues AP, Zuge SS, Paula CC, Trojahn TC. Oferta de aleitamento materno para recém-nascidos de baixo peso após a alta hospitalar. Rev Cogitare Enferm [Internet]. 2013 [acesso em 2013 jul 26];18(2):222-9. Disponível em: http://ojs.c3sl.ufpr.br/ojs2/index.php/cogitare/article/view/29609/20683.

12. Prates LA, Schmalfuss JM, Lipinski JM. Amamentação: a influência familiar e o papel dos profissionais de saúde. Rev Enferm UFSM [Internet]. 2014 [acesso em 2014 set 9];4(2):359-67. Disponível em: http://cascavel.ufsm.br/revistas/ojs2.2.2/index.php/reufsm/article/view/10631.

13. Frota MA, Mamede ALS, Vieira LJES, Albuquerque CM, Martins MC. Práticas culturais sobre o aleitamento materno entre famílias cadastradas em um Programa da Saúde da Família. Rev Esc Enferm USP [Internet]. 2009 [acesso em 18 jun 2013];43(4):895-901. Disponível: http://dx.doi.org/10.1590/S0080-62342009000400022.

14. Rivemales MC, Azevedo ACC, Bastos PL. Revisão sistemática da produção científica da enfermagem sobre o desmame precoce. Rev Enferm UERJ [Internet]. 2010 [acesso em 13 out 2012];18(1):132-7. Disponível em: http://www.facenf.uerj.br/v18n1/v18n1a23.pdf.

15. Demitto MO, Silva TC, Páschoa ARZ, Mathias TAF, Bercini LO. Orientações sobre amamentação na assistência pré-natal: uma revisão integrativa. Rev Rene [Internet]. 2010 [acesso em 2012 out 11];11(N Esp):223-9. Disponível em: http://www.revistarene.ufc.br/revista/index.php/revista/article/viewFile/494/pdfpdf.

16. Bezerra JF, Terrengui LCS. Avaliação da promoção, proteção e apoio ao aleitamento materno. Rev Enferm UNISA [Internet]. 2011 [acesso em $2013 \mathrm{fev}$ 13];12(1):5-11. Disponível em: http://www.unisa.br/graduacao/biologicas/enfer/revista/arquivos/2011-1-01.pdf.

Data de recebimento: 04/09/2014

Data de aceite: 09/03/2015

Contato com autor responsável: Laís Antunes Wilhelm

Endereço postal: Programa de Pós Graduação em Enfermagem - Centro de Ciências da Saúde - Universidade Federal de Santa Maria - Avenida Roraima n 1000, Prédio 26 - Cidade Universitária, CEP: 97105-900, Santa Maria, RS, Brasil

E-mail: laiswilhelm@gmail.com 